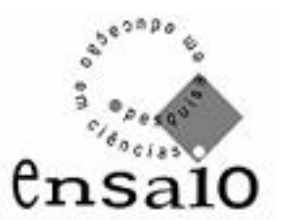

Vol. 10 №. 1 jun. 2008

\title{
Caracterização da estrutura das mostras sobre biologia em espaços não-formais de educação em ciências
}

Characterization of biology exhibits at non-formal science education spaces

Giuliano Buzá Jacobucci ${ }^{1}$

Daniela Franco Carvalho Jacobucci ${ }^{2}$

\begin{abstract}
Resumo
Os Centros e Museus de Ciências se constituem como espaços não-formais de educação em ciências, têm um papel fundamental na divulgação do conhecimento científico e tecnológico e são núcleos permanentes para discussões em diversas áreas. Pesquisas que investiguem a estrutura das mostras sobre Biologia nesses espaços ainda são raras no Brasil. Este trabalho buscou caracterizar a estrutura das exposições de Biologia em cinco Centros e Museus de Ciências Brasileiros, considerando a natureza das propostas e a diversidade das atividades para o público em geral. Foi possível observar que as mostras são organizadas por eixos temáticos, com utilização de várias estratégias para a interação com os visitantes.
\end{abstract}

Palavras-chave: Espaços não-formais de educação, Centros de Ciências, Exposições

\begin{abstract}
The Science Centers and Museums constitute non-formal science educational spaces, they have a main role in the spreading of the scientific and technological knowledge and are permanent nuclei for discussion in diverse areas. Researches which investigate the structure of Biology exhibits at these spaces are still rare in Brazil. This work traced the profile of the Biology exhibits in five Brazilian Science Centers and Museums, considering the nature of the proposals and the diversity of the activities for the general public. It was possible to observe that the exhibits are organized by thematic axles, using several strategies for the interaction with the visitors.
\end{abstract}

Keywords: Non-formal education spaces, Science Centers, Exhibits

\footnotetext{
1 Professor do Instituto de Biologia. Universidade Federal de Uberlândia - UFU. jacobucci@inbio.ufu.br

2 Pesquisadora do Grupo Formar-Ciências. Universidade Estadual de Campinas - UNICAMP. danielafcj@yahoo.com.br
} 


\section{Introdução}

Na educação não-formal, os espaços educativos localizam-se em territórios que acompanham as trajetórias de vida dos grupos e indivíduos, fora das escolas, em locais informais, locais onde há processos interativos intencionais (GOHN, 2006). Nesse contexto, os Centros e Museus de Ciências, locais de estudo dessa pesquisa, se constituem como espaços não-formais de educação em ciências, têm um papel fundamental na divulgação do conhecimento científico e tecnológico e são núcleos permanentes para discussões em diversas áreas.

Na década de 1980, surgem no Brasil os primeiros Museus de Ciências que objetivaram se projetar como instituições de comunicação, educação não-formal e difusão cultural voltadas para um público amplo e diversificado. Esse acontecimento é resultado de um processo que, no contexto internacional, teve início na década de 1960 por meio de uma intensa discussão que apontava para uma transformação da prática e do papel social dos Museus. Esses espaços concentravam-se em torno da difusão de princípios científicos, a fim de ampliar a cultura científica da sociedade. Nesse período surge, nos Estados Unidos, um tipo de Museu de contorno multidisciplinar integrando ciência, tecnologia e arte, com técnicas interativas de caráter experimental, denominado Science Center (GOUVÊA et al., 2001).

Segundo Gaspar (1993), a maioria dos novos Museus e Centros de Ciências se preocupa muito mais com o presente e o futuro ao invés de focalizar apenas o passado, evidenciando uma tendência de se tornarem espaços onde as pessoas possam ter um contato com as conquistas passadas da humanidade, mas também com a realidade dos dias atuais.

Os Centros e Museus de Ciências têm um papel fundamental na divulgação do conhecimento científico e tecnológico e são fontes vivas de informações e espaços permanentes para discussões em diversas áreas do conhecimento em Ciências. No mundo todo, podem ser observados Museus e Centros de Ciências que desenvolvem ações educativas e formativas associadas às atividades de exibição de coleções (FAHL, 2003).

Vários Centros e Museus de Ciências contam com atividades de divulgação científica de temática biológica. No entanto, tais atividades variam consideravelmente, desde visitas não monitoradas a exposições de material biológico preservado, 


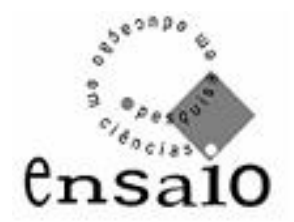

Vol. 10 №. 1 jun. 2008

passando por cursos informativos até atividades lúdicas e interativas (BRITO et al., 2005).

Segundo Marandino (2003), as exposições são elementos fundamentais de comunicação dos museus e tem por função divulgar e/ou promover a educação sobre os conhecimentos acumulados em suas coleções e produzidos nas pesquisas científicas.

Para as pesquisadoras Boisvert e Slez (1994), a obrigação dos museus de ciências como instituições educacionais informais, vai além de entreter e divertir os visitantes, e nesse sentido as exposições devem ser projetadas de tal forma que possam atrair e prender a atenção dos visitantes por um período suficientemente longo para que ocorra uma interação com as mostras e um aprendizado dos conteúdos.

Sue Allen, diretora do Departamento de Pesquisas sobre o Visitante do Museu Exploratorium, em São Francisco (EUA), acredita que as exposições em um museu de ciências devem facilitar o aprendizado das ciências, contudo necessitam também atender um público visitante diverso, hábil em fazer suas próprias escolhas sobre onde e o que visitar, o que fazer, e como interpretar suas interações. Para que as exposições se tornem ferramentas eficazes de ensino, precisam ser altamente cativantes e motivadoras para o público visitante, em cada etapa de interação, a fim de sustentar a participação de quem a visita primeiramente como uma atividade de lazer. (ALLEN, 2004).

Os resultados do trabalho de John Falk evidenciam que os visitantes de museus de ciências adquirem a informação científica factual e conceitual em conseqüência das interações relativamente breves, na ordem de 2-5 minutos, com os conjuntos de exibições relacionadas à Ciência; e o que aprendem pode ser facilitado pelo que está explicitamente e repetidamente indicado nas mensagens conceituais que são utilizadas como estratégia de comunicação das exposições (FALK, 1997).

De acordo com Valente e colaboradores (2005), nos Museus de Ciências a comunicação entre os visitantes e a Ciência é mediada por uma maior interatividade com aparatos que põem em relevo a ação do sujeito na aprendizagem. Para as autoras, as equipes profissionais desses espaços passaram a considerar em seus projetos de exposições um conjunto de evidências oriundas de pesquisas sobre ensinoaprendizagem de Ciências, e assim, a idéia do 'aprender fazendo' está sendo divulgada através das mostras. 


\section{ensaio}

Vol. 10 no. 1 jun. 2008

Mediante o exposto e tendo em vista que ainda são raras as pesquisas que enfocam as características das exposições em espaços não-formais de educação, este trabalho buscou caracterizar a estrutura das mostras de temática biológica em cinco Centros e Museus de Ciências Brasileiros, considerando a natureza das propostas e a diversidade das atividades para o público em geral.

\section{Delineamento Metodológico}

O trabalho se constitui como um estudo de caso (LÜDKE e ANDRÉ, 1986; LAVILLE e DIONNE, 1999) das características das exposições sobre Biologia em espaços não-formais de educação, definido por Megid Neto (2001) como um estudo que focaliza indivíduos ou organizações educacionais, utilizando preferencialmente técnicas e métodos característicos da abordagem qualitativa, e que considera um grande número de dimensões e variáveis a serem observadas e inter-relacionadas, para a descrição de uma realidade ampla.

A seleção dos Centros e Museus foi baseada nos dados disponíveis no site da Associação Brasileira de Centros e Museus de Ciência - http://www.abcmc.org.br, e obedeceu a três critérios: a) ser associado à ABCMC; b) possuir tempo de fundação superior a cinco anos; e c) ter exposição sobre Biologia. Buscando-se ao menos um representante de cada região do país, os Centros e Museus de Ciências foram selecionados, sendo visitados entre outubro de 2004 e dezembro de 2005.

Mediante contato prévio com os núcleos selecionados, foi requisitada autorização para visita, registro fotográfico e permanência dos pesquisadores nas dependências dos espaços, para levantamento de dados através das ações destacadas a seguir:

- Observação in loco da estrutura - Foram observadas as características das exposições de temática biológica desenvolvidas pelos núcleos, com registro fotográfico dos espaços.

- Documentação das exposições - Uma coleta de documentos e informações pertinentes à pesquisa foi realizada através de publicações e informativos gerais dos espaços.

- Entrevistas com a Equipe Técnica - Os profissionais dos núcleos foram convidados a conceder entrevistas semi-estruturadas, com gravação em áudio. 
As informações obtidas através das páginas eletrônicas, das observações in loco e das transcrições das entrevistas subsidiaram a caracterização das exposições sobre Biologia. Essa análise foi realizada com base nos seguintes parâmetros:

- Criação (própria ou de itinerância)

- Freqüência (permanente ou temporária)

- Espaço físico (área interna ou área externa)

- Acervo biológico (vivo ou preservado)

- Interatividade (participação ativa do público)

- Utilização de recursos multimídia (projeção de vídeo, sistema de áudio, Internet, hipertexto, simulações)

- Utilização de dramatizações (teatro, fantoches, mímica, danças)

- Utilização de jogos didáticos

- Monitoria

\section{Características Gerais dos Espaços}

De acordo com os critérios estabelecidos, os espaços selecionados para investigação foram: Museu de Ciências e Tecnologia (Porto Alegre - RS), Estação Ciência (São Paulo - SP), Museu da Vida (Rio de Janeiro - RJ), Espaço Ciência (Olinda - PE) e Museu Paraense Emílio Goeldi (Belém - PA). Tendo em vista que não havia um Centro ou Museu de Ciências na região Centro-Oeste que pudesse ser selecionado, essa região ficou sem representação.

Para situar o contexto dos espaços observados, apresentamos as características gerais da estrutura física e das exposições de Biologia, além de um breve histórico de cada instituição.

\section{A. MUSEU DE CIÊNCIAS E TECNOLOGIA - MCT - PUCRS}

O MCT está localizado em Porto Alegre-RS sendo de responsabilidade da Pontifícia Universidade Católica do Rio Grande do Sul (PUCRS). Teve suas origens na década de 1960 e em 1998 foi inaugurada a atual área de exposição de 22.000 m², constituída por 5 pavimentos, laboratórios de pesquisa e de apoio didático.

A exposição de Biologia contempla atividades com animais e plantas, um setor sobre biologia e reprodução humana, um setor de seres vivos com diversas atividades 


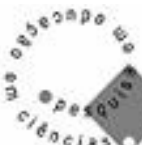 \\ ensa10}

Vol. 10 no. 1 jun. 2008

interativas sobre microorganismos, artrópodes, animais marinhos e grupos vegetais e animais diversos, atividades sobre células e meiose, um setor de aquários e um espaço reservado a crianças (Figura 1A). Há atividades para simples observação, com placas indicativas sobre a identificação do organismo e curiosidades sobre o mesmo, e atividades interativas, como jogos e computadores com hipertexto. Em certas exposições, como de aranhas e insetos, os visitantes podem manipular lupas e microscópios acoplados a televisores para observar os organismos. Algumas atividades possuem botões que, quando apertados, informam a resposta correta a uma determinada pergunta ou fazem movimentar, acender ou piscar partes do equipamento de exposição.

O layout da exposição de Biologia segue o mesmo formato de todas as exposições do museu. São utilizados painéis coloridos com ilustrações referentes ao tema e linguagem coloquial, com freqüente utilização de perguntas para despertar o interesse do público em relação ao material exposto (Figura 1B).

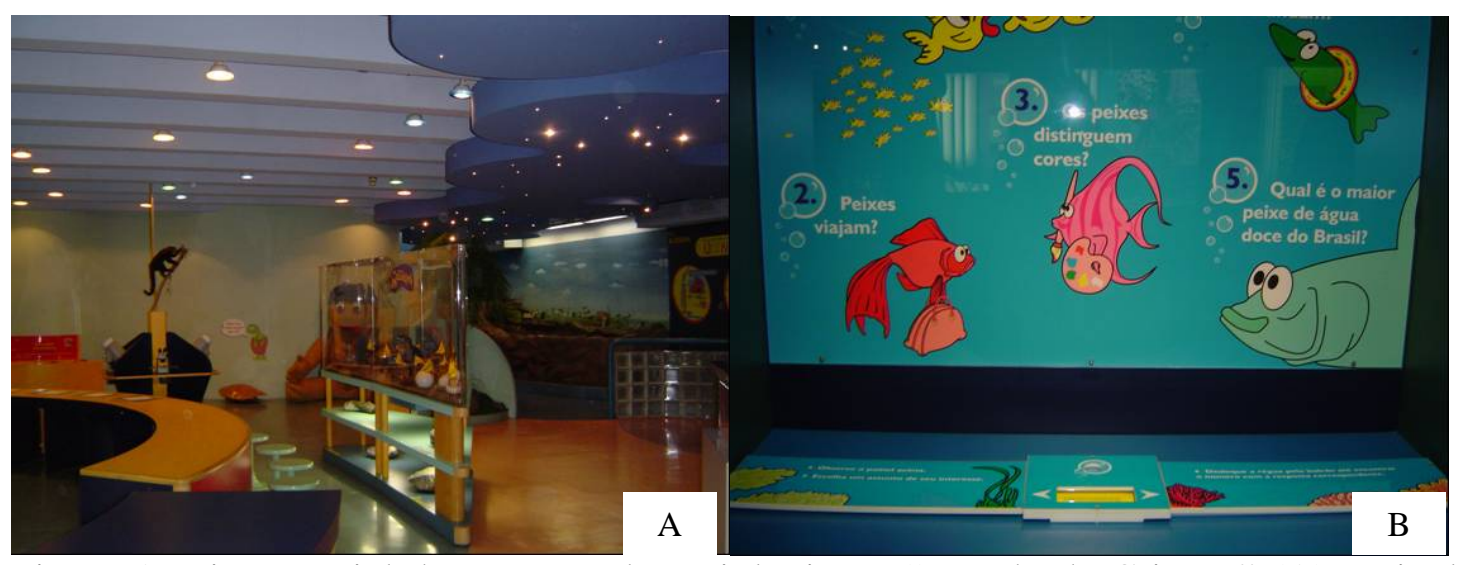

Figura 1. Vista parcial da mostra sobre Biologia no "Mundo da Criança” (A); Painel expositivo sobre a Biologia de peixes (B)

\section{B. ESTAÇÃO CIÊNCIA}

A Estação Ciência foi inaugurada em 1987 pelo Conselho Nacional de Desenvolvimento Científico e Tecnológico (CNPq) e, a partir de 1990, tem sido administrada pela Universidade de São Paulo. A Estação Ciência é aberta à visitação pública em um prédio de $4.600 \mathrm{~m}^{2}$ de antiga tecelagem da década de 1930 (Figura 2A), na cidade de São Paulo-SP. 


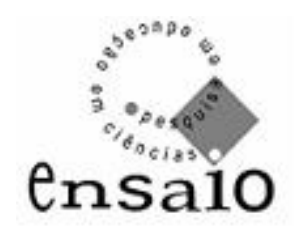

Vol. 10 №. 1 jun. 2008

A exposição de Biologia engloba mostras de biologia aquática, corpo humano, plantas carnívoras e biologia de serpentes e invertebrados peçonhentos. A mostra de biologia aquática conta com aquários de água doce e marinhos e um tanque de toque de invertebrados marinhos (Figura 2B), que podem ser manipulados pelos visitantes em horários específicos e sob supervisão de monitores. A mostra do corpo humano inclui modelos anatômicos, painéis explicativos sobre a biologia da reprodução e bonecos de pano gigantes que são apresentados ao público infantil através de dramatização para a visualização da distribuição dos órgãos do corpo humano. $\mathrm{Na}$ Parada Butantan há diversos terrários com serpentes, anfíbios e invertebrados peçonhentos, além de um local com mesas e um armário gaveteiro, onde o visitante pode escolher diferentes kits sobre animais peçonhentos para manipulação e estudo. No período de realização da visita investigativa, havia uma exposição temporária sobre recursos hídricos recebida por itinerância, constituída basicamente por painéis explicativos.

O layout da exposição de Biologia é centrado em painéis explicativos com descrição do material exposto, com linguagem coloquial e elementos gráficos coloridos. As placas de identificação dos aquários permitem ao visitante localizar apenas algumas espécies de organismos aquáticos em exposição, por comparação com as fotografias disponíveis nas placas. Os terrários da Parada Butantan possuem pequenos textos no vidro externo sobre os animais em exposição, além de uma caracterização visual que simula o ambiente natural dos organismos.

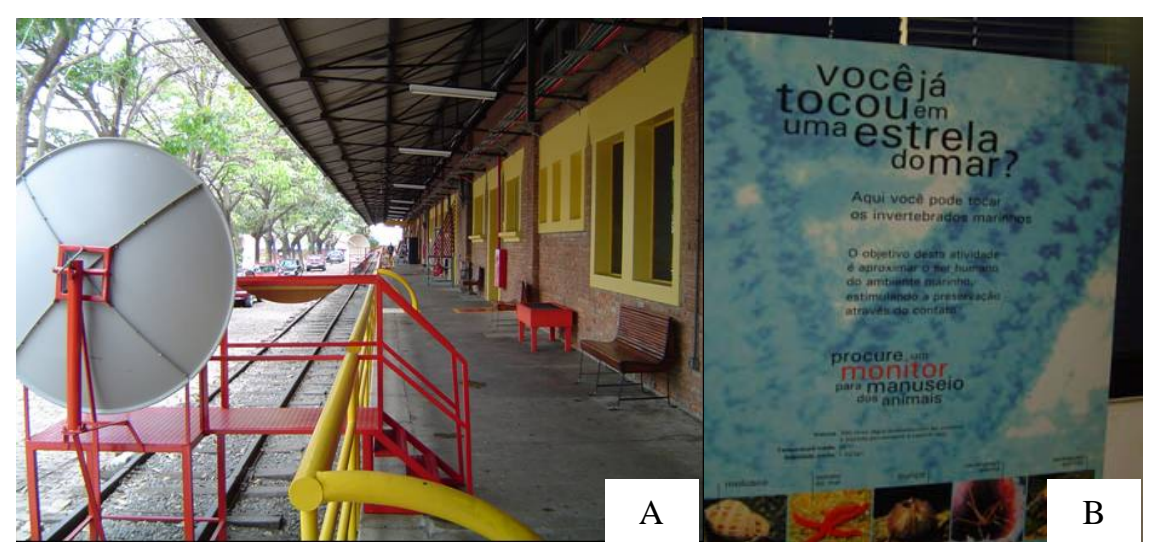

Figura 2. Entrada principal da Estação Ciência (A); Painel sobre o tanque de toque de invertebrados marinhos (B) 


\section{MUSEU DA VIDA}

\section{ensa10}

O Museu da Vida situa-se no Rio de Janeiro-RJ, vinculado à Fundação Oswaldo Cruz (FIOCRUZ), foi criado em 1998 e aberto ao público em 1999. O museu está inserido no campus da FIOCRUZ e é composto por cinco estruturas interligadas: o Centro de Recepção, o Espaço Biodescoberta, o Parque da Ciência (Figura 3A), o Ciência em Cena e o Passado e Presente.

O Espaço Biodescoberta possui no saguão principal, dois grandes painéis da mata atlântica, jogos da memória e um mapa mundi, com informações sobre a distribuição dos animais no mundo e no Brasil. Há uma grande sala de exposição, onde temas relativos à vida são tratados em saletas semi-abertas, por meio de material informativo impresso e eletrônico (computadores com hipertextos) e materiais biológicos que podem ser manipulados pelo público com o auxílio de monitores. O Parque da Ciência fica ao ar livre, onde há várias estruturas coloridas e de grandes dimensões que remetem a uma idéia de parque de diversões. Das diversas estruturas do parque, a célula animal gigante (Figura 3B) é a que mais se destaca, visto que os visitantes podem escalar a estrutura de concreto que representa as organelas. O Ciência em Cena é um segmento do museu que utiliza elementos artístico-culturais para a divulgação científica, abordando a ciência no cotidiano das pessoas.

O layout das exposições de Biologia do Espaço Biodescoberta e do Parque da Ciência é muito similar, pois ambas utilizam painéis explicativos, com figuras e textos coloridos sobre um dado conteúdo. No Parque da Ciência os painéis são confeccionados em metal, devido à exposição ser realizada permanentemente em área aberta. A maioria dos painéis explicativos do Espaço Biodescoberta está fixada na parede, delimitando o espaço de cada mostra. A linguagem coloquial é utilizada na maioria dos painéis, no entanto, alguns textos apresentam linguagem formal, muito próxima à de um artigo científico. 


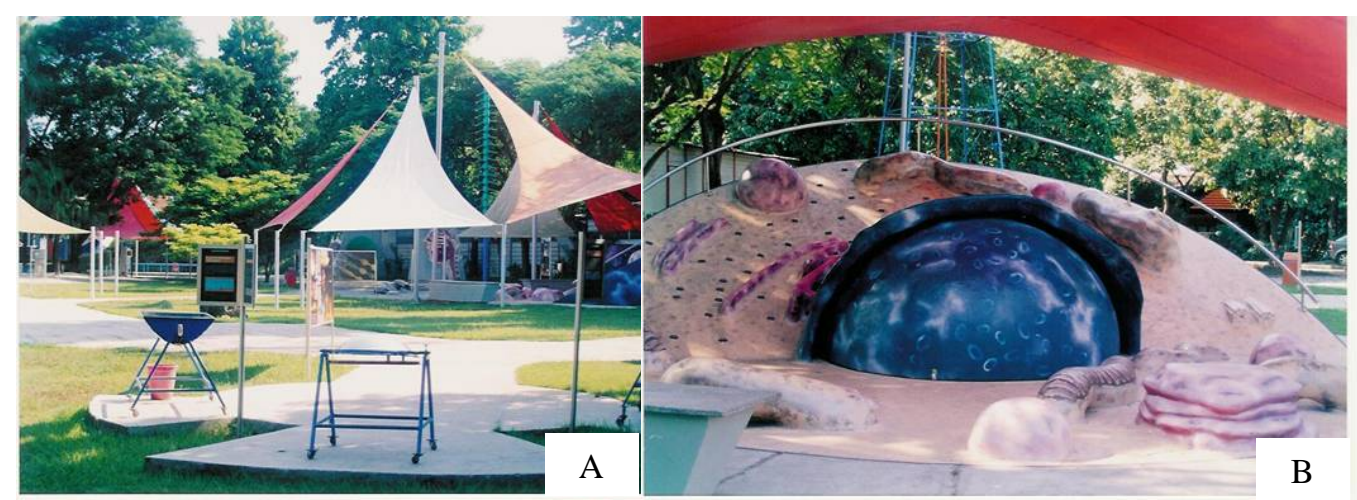

Figura 3. Vista parcial do "Parque da Ciência” (A); Estrutura da célula animal gigante no "Parque da Ciência” (B)

\section{ESPAÇO CIÊNCIA}

O Espaço Ciência foi inaugurado em 1994 pela Secretaria de Ciência, Tecnologia e Meio Ambiente de Pernambuco. Atualmente ocupa uma área de 120 mil $\mathrm{m}^{2}$ no Complexo de Salgadinho, entre as cidades de Olinda e Recife, em Pernambuco. O local tem um manguezal de $19 \mathrm{mil} \mathrm{m}^{2}$, um espaço de exposição a céu aberto e a sede (Figura 4A), com laboratórios didáticos e setor administrativo.

O Parque da Descoberta Científica abriga o manguezal e exposições de ciências a céu aberto e foi elaborado para integrar visitantes com necessidades especiais. Sua pavimentação muda de textura de acordo com o tema abordado na exposição, além de haver diversos equipamentos que permitem a interação por meio do toque. O Parque da Descoberta Científica pode ser explorado de duas maneiras, pela trilha Ecológica que abriga o manguezal e discute questões sócio-ambientais, ou pela trilha da Descoberta. A trilha da Descoberta engloba cinco áreas temáticas: Água, Movimento, Percepções, Terra e Espaço. Em todas as áreas temáticas há estruturas em que o visitante pode subir, balançar, pular e escorregar, pois simulam brinquedos de parque de diversões. Na área da Terra, grandes esculturas em fibra de vidro representam dinossauros (Figura 4B) e fósseis de animais brasileiros em escala real.

O laboratório didático de Biologia é utilizado para a realização de atividades monitoradas. Há bancadas de trabalho, diversos modelos de corpo humano e um acervo de material biológico preservado disponível para observação e manipulação. 


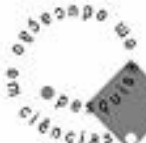 \\ ensa10}

Vol. 10 no. 1 jun. 2008

No período da visita investigativa, havia uma exposição temporária recebida por itinerância sobre os cinqüenta anos da descoberta do DNA. A base da mostra consistia de painéis explicativos, no entanto, o Espaço Ciência incluiu atividades interativas sobre clonagem e uma instalação artística sobre a estrutura do DNA.

O Parque da Descoberta Científica utiliza como recurso de comunicação com o público visitante os próprios modelos e aparatos expostos, não havendo de forma geral, painéis explicativos e as informações são trabalhadas por monitores.

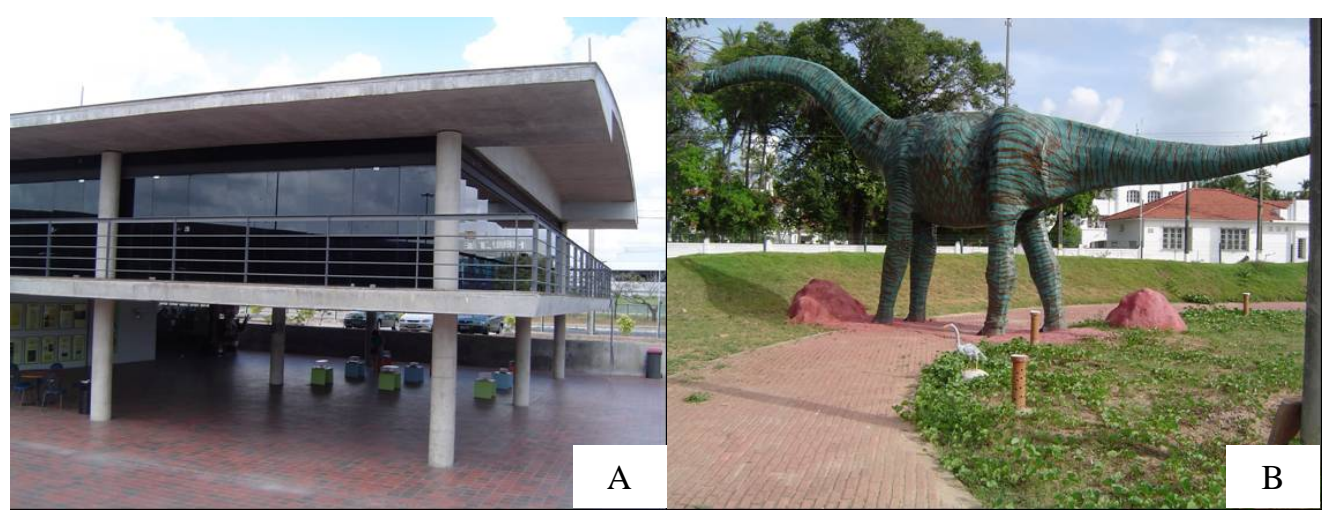

Figura 4. Vista parcial da sede do Espaço Ciência (A); Escultura de um dinossauro no "Parque da Descoberta Científica (B)

\section{E. MUSEU PARAENSE EMÍLIO GOELDI}

O Museu Paraense Emílio Goeldi foi fundado em 1866 como uma unidade de pesquisas e inventário da Amazônia, e desde 1985 está vinculado ao Ministério de Ciência e Tecnologia. O museu possui três bases físicas: o Parque Zoobotânico, o Campus de Pesquisa e a Estação Científica Ferreira Penna. O Parque Zoobotânico é aberto à visitação pública e fica localizado na região central de Belém-PA.

A estrutura do Parque Zoobotânico se assemelha à de um grande zoológico, com trilhas em chão batido por entre a mata (Figura 5A), que dão acesso aos recintos e viveiros de animais brasileiros, principalmente da região amazônica. É possível observar animais em vias de extinção, como o peixe boi, e espécies vegetais raras da Amazônia. O aquário tem entrada controlada, com limitação do número de visitantes, e apresenta diversas espécies de peixes amazônicos além de serpentes e quelônios.

Algumas espécies vegetais apresentam plaquetas de identificação com nome científico e nome popular. Os recintos de animais possuem painéis com fotografia, 


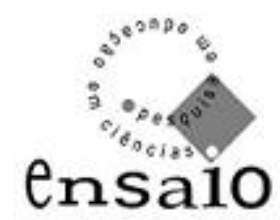

Vol. 10 no. 1 jun. 2008

nome científico e popular das espécies e informações sucintas sobre distribuição geográfica, hábito alimentar e reprodução (Figura 5B). No aquário a observação dos organismos e das placas de identificação das espécies é difícil, em função do ambiente ser pouco iluminado. É possível encontrar facilmente monitores, que somente informam dados adicionais aos visitantes quando questionados.

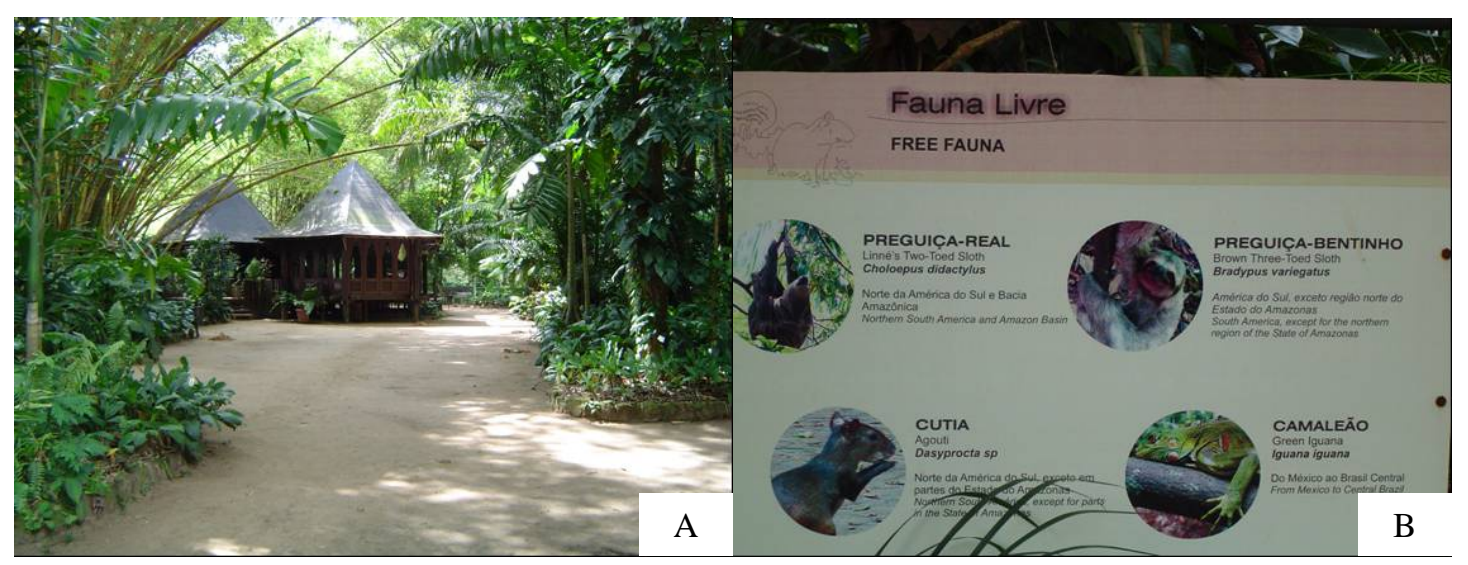

Figura 5. Trilha do "Parque Zoobotânico" (A); Painel expositivo com fotografias sobre a fauna livre do "Parque Zoobotânico" (B)

\section{Estrutura das Mostras sobre Biologia}

Os núcleos de divulgação científica investigados são muito diferentes entre si no que se refere à estrutura física, no entanto, todas as exposições sobre Biologia apresentam grande diversidade de recursos expositivos com enfoque temático.

Em um estudo sobre o processo de educação e divulgação da ciência em bioexposições em cinco Museus de Ciências Brasileiros, Marandino (2003) identificou dois grandes grupos de estratégias expositivas: (I) aquele que reflete diretamente o conhecimento científico num determinado período histórico; e outro (II) que utiliza diferentes estratégias expositivas em função de eixos temáticos. Utilizamos esse trabalho como referencial teórico da pesquisa que realizamos, tendo em vista que é a única investigação dessa natureza realizada no Brasil. As exposições do Museu da Vida e da Estação Ciência foram caracterizadas pela referida autora como pertencentes ao grupo II. Os demais Centros e Museus de Ciências investigados em nosso trabalho também estruturam suas propostas expositivas sobre Biologia em função de eixos temáticos. 


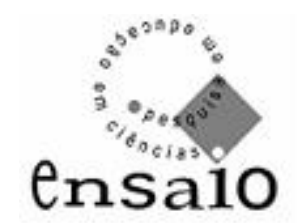

Vol. 10 no. 1 jun. 2008

Em função dos Centros e Museus de Ciências estudados apresentarem exposições com várias estratégias de comunicação com o público, buscou-se analisar elementos significativos da estrutura dessas mostras que permitissem diferenciá-las e discutí-las. Para tanto, utilizou-se o conjunto de parâmetros descritos de forma resumida no Quadro 1.

Quadro 1. Descrição sumária dos elementos presentes nas exposições dos núcleos de divulgação científica.

\begin{tabular}{|c|c|c|c|c|c|c|}
\hline & & \multicolumn{5}{|c|}{ Núcleos } \\
\hline \multicolumn{2}{|l|}{ Parâmetros } & $\mathbf{A}$ & B & $\mathbf{C}$ & $\mathbf{D}$ & $\mathbf{E}$ \\
\hline \multirow{2}{*}{ Criação } & Própria & $\mathrm{X}$ & $\mathrm{X}$ & $\mathrm{X}$ & $\mathrm{X}$ & $\mathrm{X}$ \\
\hline & Itinerância & & $\mathrm{X}$ & & $\mathrm{X}$ & \\
\hline \multirow{2}{*}{ Freqüência } & Permanente & $\mathrm{X}$ & $\mathrm{X}$ & $X$ & $\mathrm{X}$ & $\mathrm{X}$ \\
\hline & Temporária & & $\mathrm{X}$ & & $\mathrm{X}$ & \\
\hline \multirow{2}{*}{ Espaço físico } & Área interna & $\mathrm{X}$ & $\mathrm{X}$ & $\mathrm{X}$ & $\mathrm{X}$ & $\mathrm{X}$ \\
\hline & Área externa & & & $X$ & $\mathrm{X}$ & $\mathrm{X}$ \\
\hline \multirow{2}{*}{ Acervo biológico } & Vivo & $\mathrm{X}$ & $\mathrm{X}$ & & $\mathrm{X}$ & $\mathrm{X}$ \\
\hline & Preservado & $\mathrm{X}$ & $\mathrm{X}$ & $X$ & $\mathrm{X}$ & \\
\hline \multirow{2}{*}{ Interatividade } & Sim & $\mathrm{X}$ & $\mathrm{X}$ & $X$ & $\mathrm{X}$ & $\mathrm{X}$ \\
\hline & Não & & & & & \\
\hline \multirow{2}{*}{ Utilização de recursos multimídia } & Sim & $\mathrm{X}$ & $\mathrm{X}$ & $X$ & $\mathrm{X}$ & \\
\hline & Não & & & & & $\mathrm{X}$ \\
\hline \multirow{2}{*}{ Utilização de dramatizações } & Sim & & $\mathrm{X}$ & $X$ & & \\
\hline & Não & $\mathrm{X}$ & & & $\mathrm{X}$ & $\mathrm{X}$ \\
\hline \multirow{2}{*}{ Utilização de jogos didáticos } & Sim & $\mathrm{X}$ & $\mathrm{X}$ & $\mathrm{X}$ & $\mathrm{X}$ & \\
\hline & Não & & & & & $\mathrm{X}$ \\
\hline \multirow{2}{*}{ Monitoria } & Sim & $\mathrm{X}$ & $\mathrm{X}$ & $\mathrm{X}$ & $\mathrm{X}$ & $\mathrm{X}$ \\
\hline & Não & & & & & \\
\hline
\end{tabular}

A. Museu de Ciências e Tecnologia; B. Estação Ciência; C. Museu da Vida; D. Espaço Ciência; E. Museu Paraense Emílio Goeldi. 


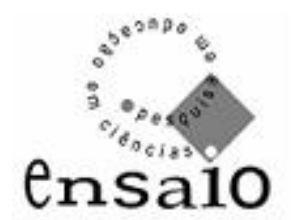

Vol. 10 no. 1 jun. 2008

A recepção de exposições através de itinerância propicia à Estação Ciência e ao Espaço Ciência agregar, durante um determinado período, uma diversidade temática adicional à mostra permanente, em função da contribuição de outras instituições de divulgação científica. Esses espaços também produzem pequenas mostras itinerantes sobre diversos temas biológicos que são exibidas principalmente em escolas, em eventos como feiras de ciências, mediante agendamento.

As exposições localizadas em áreas externas do Museu da Vida, Espaço Ciência e Museu Paraense Emílio Goeldi, recebem os nomes Parque da Ciência, Parque da Descoberta Científica e Parque Zoobotânico, respectivamente. Nesses locais, a constituição e a disposição das exposições foram planejadas buscando-se uma integração com os espaços externos. A denominação parque unida ao local de exposição ao ar livre remete à idéia de incluir o lazer como um elemento facilitador do processo de divulgação científica. Para o pesquisador Ronen Mir, o número de centros de ciências ao ar livre que incluem exposições interativas do tipo hands-on tem crescido recentemente em todo o mundo, não somente pela atração que geram em crianças e adolescentes, mas também porque os centros de ciências ao ar livre não requerem edifícios, e assim sua execução pode ser mais rápida e econômica (MIR, 2003).

Os Centros e Museus de Ciências que possuem acervo vivo incluem em suas exposições um elemento diferencial, na medida em que, a interação com organismos vivos, mesmo que em ambiente artificial (recintos, terrários, aquários) propicia uma experiência sensorial mais realística do público com os animais, o que seria impossível vivenciar com animais preservados e modelos.

Todos os núcleos estudados apresentam estratégias de exposição que estimulam a interatividade, fazendo uso de uma série de aparatos visuais como painéis explicativos, objetos para manipulação e atividades do tipo hands on. O Museu Paraense Emílio Goeldi apesar de não utilizar essas ferramentas, apresenta caráter interativo pela natureza da relação do público com os animais vivos na exposição.

A opção de inserir atividades de interação com os visitantes nas exposições está relacionada às propostas teórico-metodológicas de ensino-aprendizagem adotadas por cada um dos núcleos de divulgação científica. Além disso, as mostras interativas estão sendo largamente empregadas por espaços não-formais de educação porque esses locais precisam estruturar suas atividades de forma que o público possa se interessar 


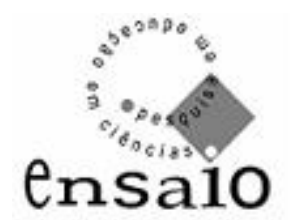

Vol. 10 no. 1 jun. 2008

pelos assuntos tratados logo na primeira visita, uma vez que não há como prever quando os visitantes retornarão ao espaço. Segundo Maurício (1992), a inovação desses espaços não está somente em aparatos de acionamento de máquinas e botões, e sim, em exibições interativas que propiciam ao visitante tomar decisões e descobrir suas conseqüências.

A pesquisa de Rix e McSorley (1999) aborda interações de crianças com as exposições de museus de ciências e sugere que embora as crianças pareçam fazer alguns ganhos na sua aprendizagem do conhecimento científico, habilidades e processos científicos, os maiores ganhos foram no desenvolvimento de atitudes positivas para a Ciência. Para o professor, é uma oportunidade para trabalhar em sala de aula a partir desse entusiasmo das crianças com a experiência interativa vivenciada.

Trabalhos recentes apontam os painéis de toque ${ }^{1}$ como uma estratégia inovadora de interatividade com o público em museus de ciências e jardins zoológicos (TUNNICLIFFE e LATERVEER-DE BEER, 2002; LINDEMANN-MATTHIES e KAMER, 2006). Nesses painéis, as informações sobre a mostra se relacionam com os objetos expostos de tal forma que luzes se acendem ou sons são emitidos quando o visitante estabelece essas relações. Embora vários recursos interativos sejam adotados pelos núcleos de divulgação científica estudados, os painéis de toque não foram observados no período investigado.

Com exceção do Museu Paraense Emílio Goeldi, os demais centros investigados fazem uso de recursos multimídia na mediação com o público. A adoção desses recursos representa a incorporação de tecnologias de vanguarda, além de possibilitar o contato do visitante com esse tipo de mídia.

A Estação Ciência e o Museu da Vida incluem elementos culturais e artísticos na mediação com o público, através das dramatizações, sendo essa uma estratégia pouco usual de divulgação científica nos meios acadêmicos. Já a utilização de jogos didáticos pela maioria dos núcleos, remete ao lúdico e à possibilidade de aliar brincadeiras à divulgação científica.

A monitoria é um elemento comum a todos os núcleos de divulgação científica e representa uma estratégia complementar de mediação com o público, no entanto pouquíssimos estudos abordam a relação dos monitores, professores e público

\footnotetext{
${ }^{1}$ Touch Tables
} 


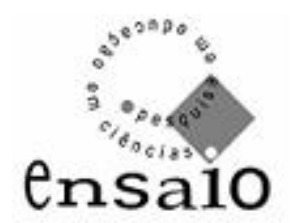

Vol. 10 no. 1 jun. 2008

visitante. Uma pesquisa atual sobre educação em museus investigou visitas escolares monitoradas a museus de história natural. A análise revelou que os monitores utilizam com freqüência o jargão científico e as perguntas elaboradas são de baixa complexidade, o que limita a explanação dos fenômenos. Outro ponto observado foi de que a minoria dos professores se envolve nas atividades, seja de forma a ajudar o monitor a esclarecer aspectos da exposição ou em ajudar os estudantes a compreender as explanações do monitor (TAL e MORAG, 2007).

A característica das exposições sobre Biologia nos cinco Centros e Museus de Ciências brasileiros investigados é de mostras biológicas por eixos temáticos, com utilização de várias estratégias expositivas para a interação com os visitantes, sendo que cada um dos núcleos faz uso de recursos de divulgação científica específicos, o que resulta em exposições muito diferenciadas entre si no que se refere à estrutura das mostras.

Ainda há muito para se investigar no campo da educação em espaços nãoformais, e nesse sentido, estudos futuros que procurem relacionar a estrutura das mostras sobre Biologia com o processo de aquisição do conhecimento científico poderão contribuir com novas informações a respeito dos elementos que atraem o visitante a uma dada exposição.

\section{Agradecimentos}

Agradecemos o apoio financeiro do Conselho Nacional de Desenvolvimento Científico e Tecnológico - CNPq e da Pró-Reitoria de Pesquisa e Pós-graduação da Universidade Federal de Uberlândia.

\section{Referências Bibliográficas}

ALLEN, Sue. Designs for Learning: Studying science museum exhibits that do more than entertain. Hoboken: Science Education. 88: 17-33 (Suppl. 1), 2004.

BOISVERT, Dorothy Lozowski; SLEZ, Brenda Jochums. The Relationship between Visitor Characteristics and Learning-Associated Behaviors in a Science Museum Discovery Space. Hoboken: Science Education. 78 (2): 137-148, 1994.

BRITO, Fátima; FERREIRA, José Ribamar; MASSARANI, Luisa. (eds). Centros e Museus de Ciências do Brasil. Rio de Janeiro: ABCMC, UFRJ, Casa da Ciência: FIOCRUZ, Museu da Vida, 2005. 


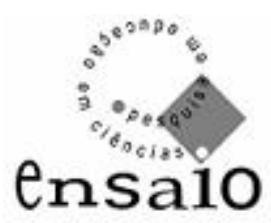

Vol. 10 no. 1 jun. 2008

FAHL, Deise Dias. Marcas do ensino escolar de Ciências presentes em Museus e Centros de Ciências: um estudo da Estação Ciência - São Paulo e do Museu Dinâmico de Ciências de Campinas (MDCC). Dissertação (Mestrado em Educação), Faculdade de Educação, Universidade Estadual de Campinas, Campinas, SP. 2003.

FALK, John. Testing a Museum Exhibition Design Assumption: effect of explicit labeling of exhibit clusters on visitor concept development. Hoboken: Science Education. 81 (6): 679-687, 1997.

GASPAR, Alberto. Museus e Centros de Ciências - Conceituação e Proposta de um referencial teórico. Tese (Doutorado em Didática), Faculdade de Educação, Universidade de São Paulo, São Paulo, SP. 1993.

GOHN, Maria da Glória. Non-formal education, civil society participation and councils structures in the schools. Rio de Janeiro: Ensaio: avaliação e políticas públicas em Educação. 14 (50): 27-38, 2006.

GOUVÊA, Guaracira; VALENTE, Maria Esther; CAZELLI, Sibele; MARANDINO, Martha. Redes Cotidianas de Conhecimentos e os Museus de Ciências. Brasília: Parcerias Estratégicas. 11: 169-174, 2001.

LAVILLE, Christian; DIONNE, Jean. A construção do saber: manual de metodologia da pesquisa em ciências humanas. Porto Alegre: Editora Artes Médicas Sul; Belo Horizonte: Editora UFMG, 1999.

LINDEMANN-MATTHIES, Petra; KAMER, Tobias. The Influence of an Interactive Educational Approach on Visitors' learning in a Swiss Zoo. Hoboken: Science Education. 90:296-315, 2006.

LÜDKE, Hermengarda Alves Ludke Menga; ANDRÉ, Marli. Pesquisa em educação: abordagens qualitativas. São Paulo: EPU, 1986.

MARANDINO, Martha. Enfoques de Educação e Comunicação nas Bioexposições de Museus de Ciências. Bauru: Revista Brasileira de Pesquisa em Educação em Ciências. 3(1): 103-109, 2003.

MAURÍCIO, Luiz Alberto. Centro de Ciências: origens e desenvolvimento - uma relação sobre seu papel e possibilidade dentro do contexto educacional. São Paulo, 1992. Dissertação de Mestrado. Instituto de Física/Faculdade de Educação Universidade de São Paulo.

MEGID NETO, Jorge. Elaboração de Projetos Técnicos de Pesquisa. Campinas:

Faculdade de Educação - UNICAMP, 2001.

MIR, Ronen. Outdoor Science Centres. Olney: International Journal of Technology Management. 25 (5): 390-404, 2003.

RIX Carl; MCSORLEY, Joseph. An Investigation into the role that School-based Interactive Science Centres may Play in the Education of Primary-aged Children. Earley: International Journal of Science Education. 21 (6): 577-593, 1999.

TAL, Tali; MORAG, Orly. School Visits to Natural History Museums: Teaching or Enriching? Hoboken: Journal of Research in Science Teaching. 44 (5): 747-769, 2007.

TUNNICLIFFE Sue Dale; LATERVEER-DE BEER Manon. An Interactive Exhibition about Animal Skeletons: did the visitors learn any zoology? London: Journal of Biological Education. 36 (3): 130-134, 2002.

VALENTE, Maria Esther; CAZELLI, Sibele; ALVES, Fátima. Museus, Ciência e Educação: novos desafios. Rio de Janeiro: História, Ciências, Saúde-Manguinhos. 12: 183-203, 2005. 


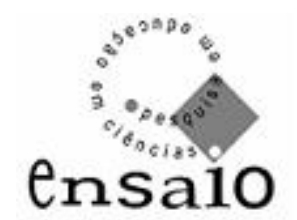

Vol. 10 no. 1 jun. 2008

DATA DE RECEBIMENTO: 16/10/2007

DATA DE APROVAÇÃO: 03/01/2008

DATA DE VERSÃO FINAL: 18/02/2008 